\title{
Acute pancreatitis induced by vegetable fibers
}

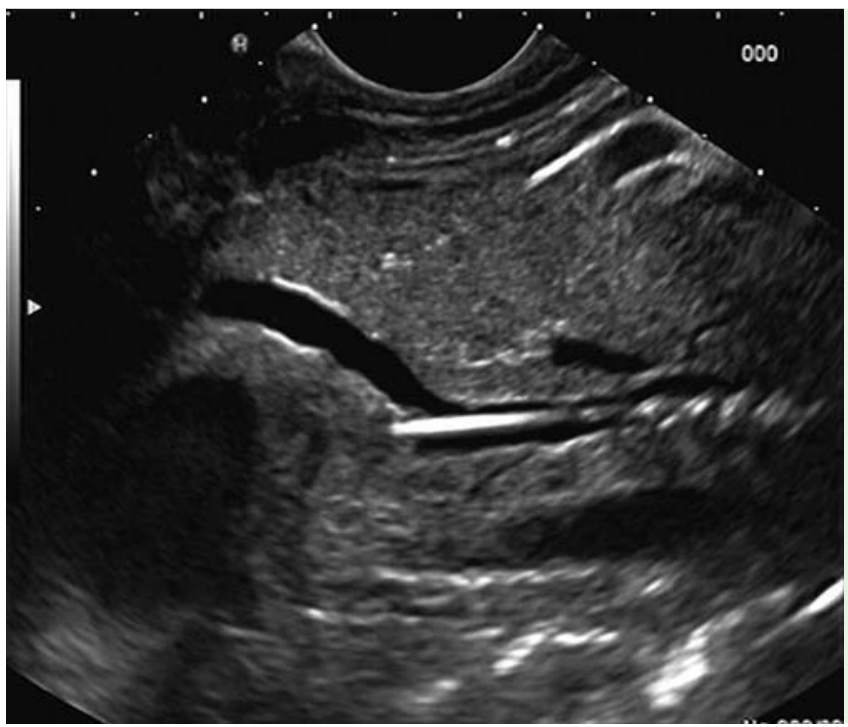

Fig. 1 Endosonographic image from a 38-year-old woman referred with recurrent acute pancreatitis showing a 6-cm hyperechoic "tubular structure" in the pancreatic duct, with multiple irregular spots and a leaf-like ending, perfectly fitting the duct, up to the pancreatic isthmus.

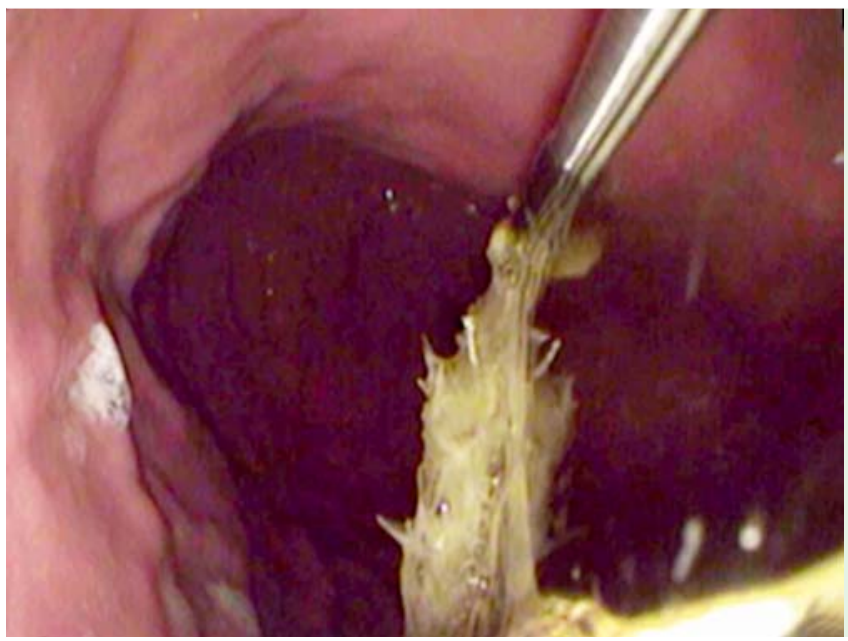

Fig. 3 Endoscopic image of removal of the vegetable fiber from the papilla using a biopsy forceps.

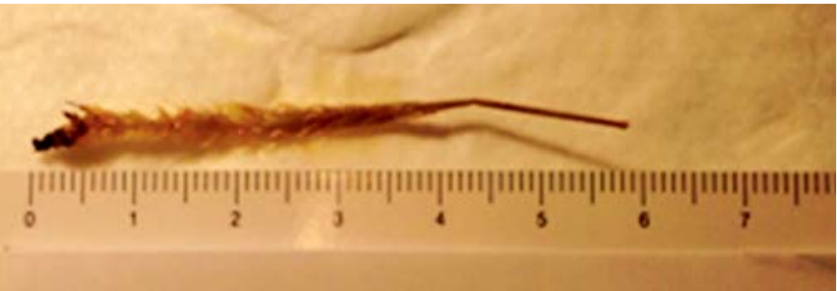

Fig. 4 Macroscopic examination showing that the foreign body was a vegetable ear.

Acute pancreatitis induced by ingested foreign bodies is a rare entity [ $1-5]$. We report an unusual case of acute pancreatitis caused by a foreign body which had migrated into the main pancreatic duct. A 38-year-old woman was referred to our unit with recurrent acute pancreatitis. Serum amylase (286U/L) and lipase $(721 \mathrm{U} / \mathrm{L})$ were elevated, and she complained of severe abdominal pain radiating to her back. The patient denied recent use of alcohol or drugs and also denied previous pancreatic or hepato-biliary disease, and surgical operations. Abdominal ultrasound and contrast-enhanced computed tomography (CT) showed a dilation of both the common bile duct and pancreatic duct. Magnetic resonance cholangiopancreatography (MRCP) showed a 3-mm calcification in the pancreatic duct; the duct was slightly dilated. Endoscopic ultrasound (EUS) identified a 6-cm hyperechoic

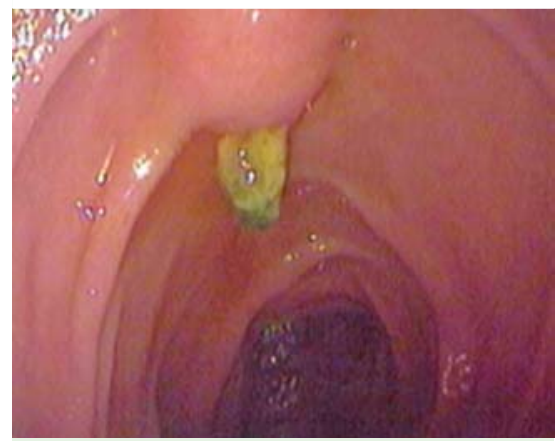

Fig.2 Endoscopic image of one end of the fiber in the pancreatic duct, protruding out of the papilla into the duodenal lumen.

"tubular structure" in the pancreatic duct, with multiple irregular spots, and a leaflike ending, perfectly fitting the duct, up to the pancreatic isthmus ( $\mathrm{Fig} .1$ ), and protruding out of the papilla into the duodenal lumen ( $\bullet$ Fig. 2). The "tubular structure" was removed endoscopically using a biopsy forceps ( $\bullet$ Fig.3). Macroscopic examination showed that the foreign body was in fact a vegetable ear ( Fig. 4). The patient was discharged after 2 days following rapid normalization of serum pancreatic enzymes. At 3-month follow-up, the patient was totally asymptomatic.

In this case, EUS proved to be a valuable tool in detecting a pancreatic foreign body, while other imaging techniques (abdominal ultrasound, CT, MRCP) were inconclusive or misleading.

\section{Endoscopy_UCTN_Code_CCL_1AZ_2AF}

\section{Competing interests: None}

\section{Sabrina Gloria Giulia Testoni, Maria Chiara Petrone, Paolo Giorgio Arcidiacono}

Gastroenterology and Gastrointestinal Endoscopy Unit, San Raffaele Scientific Institute, Vita-Salute San Raffaele University, Milan, Italy

\section{References}

$1 \mathrm{Kim} \mathrm{KH,} \mathrm{Woo} \mathrm{EY,} \mathrm{Rosato} \mathrm{EF} \mathrm{et} \mathrm{al.} \mathrm{Pancreatic}$ foreign body: ingested toothpick as a cause of pancreatitis and hemorrhage. Gastrointest Endosc 2004; 59: 147-149

2 Kim JH, Chang JH, Nam SM et al. Duodenal obstruction following acute pancreatitis caused by a large duodenal diverticular 
bezoar. World J Gastroenterol 2012; 18 : $5485-5488$

3 Honda S, Miyagi H, Okada T. An unusual cause of acute pancreatitis in a 6-year-old boy. Gastroenterology 2012; 142: e16-e17

4 Yasuda T, Kawamura S, Shimada E et al. Fish bone penetration of the duodenum extending into the pancreas: report of a case. Surg Today 2010; 40: 676-678

5 David X, Bories P, Parelon G et al. Acute pancreatitis induced by "herbs of Provence". Lancet 1991; 337: 311

\section{Bibliography}

DOI http://dx.doi.org/

10.1055/s-0034-1391129

Endoscopy 2015; 47: E36-E37

(c) Georg Thieme Verlag KG

Stuttgart · New York

ISSN 0013-726X

\section{Corresponding author}

Sabrina Gloria Giulia Testoni, MD

Gastroenterology and Gastrointestinal Endoscopy Unit

San Raffaele Scientific Institute

Vita-Salute San Raffaele University via Olgettina 58

20132 Milan

Italy

Fax: +39-2-26342145

testoni.sabrinagloriagiulia@hsr.it 